\title{
Case Report of Infectious Spondylitis Caused by Kytococcus sedentarius
}

\author{
Kyoung Ree Lim ${ }^{1,2}$, Jun Seong Son ${ }^{2}$ and Soo-youn Moon ${ }^{2, *}$ \\ 1 Department of Medicine, College of Medicine, Kangwon National University, Chuncheon 24289, Korea; \\ idkrlim@naver.com \\ 2 Division of Infectious Diseases, Department of Internal Medicine, \\ Kyung Hee University Hospital at Gangdong, Seoul 05278, Korea; isonjs@naver.com \\ * Correspondence: sooyounmon78@gmail.com; Tel.: +82-2-440-6083
}

check for

updates

Citation: Lim, K.R.; Son, J.S.; Moon, S.-y. Case Report of Infectious Spondylitis Caused by Kytococcus sedentarius. Medicina 2021, 57, 797. https://doi.org/10.3390/

medicina57080797

Academic Editor: Modra Murovska

Received: 7 July 2021

Accepted: 31 July 2021

Published: 2 August 2021

Publisher's Note: MDPI stays neutral with regard to jurisdictional claims in published maps and institutional affiliations.

\begin{abstract}
Background: Kytococcus species has not been considered a pathogen, but infections caused by this species are increasing. There are several cases of infections caused by Kytococcus sedentarius, but no case of infectious spondylitis has been reported yet. Case presentation: A 79-year-old female patient was hospitalized because of back pain for several months. She was diagnosed with infectious spondylitis, and K. sedentarius was cultured from the pus and specimen obtained during the surgical procedure. The patient recovered completely without recurrence after 6 months of treatment with ciprofloxacin alone for 8 weeks. Conclusion: This is the first case report of infectious spondylitis caused by K. sedentarius.
\end{abstract}

Keywords: Kytococcus sedentarius; infectious spondylitis; Kytococcus spp.; spine infection

\section{Introduction}

K. sedentarius is generally considered a harmless commensal, and infection caused by this organism is not common [1,2]. Kytococci are gram-positive, pigmented, nonencapsulated, non-motile, aerobic, catalase-positive cocci appearing in pairs or tetrads. The genus consists of three species: K. sedentarius, K. schroeteri, and K. aerolatus. [3]

Infectious spondylitis is an infectious disease of the bony spinal column and the intervertebral discs, which is increasing in the aging population [4]. Magnetic resonance imaging (MRI) and computed tomography (CT) are good tools in diagnosing infectious spondylitis and detecting complications such as an abscess [5].

To our knowledge, there have been no reports of spondylitis caused by K. sedentarius. Here, we present a case of postoperative spondylitis due to K. sedentarius.

This case report was reviewed by the institutional review board of the hospital. As we could not contact the patient or any family members after treatment, the informed consent was waivered by IRB.

\section{Case Presentation}

A 79-year-old woman was admitted to a hospital for increasing back pain and left leg radiating pain for several months. She had type 2 diabetes mellitus and hypertension and was taking medications. She was treated with physiotherapy and injection for her back and radiating pain every other week for several months before her back pain was exacerbated.

On admission, her vital signs were stable, with a blood pressure of $138 / 75 \mathrm{mmHg}$, pulse rate of $75 / \mathrm{min}$, respiration rate of $20 / \mathrm{min}$, and body temperature of $36.7^{\circ} \mathrm{C}$. Blood tests on admission showed an elevated erythrocyte sedimentation rate (ESR) of $73 \mathrm{~mm} / \mathrm{h}$ and C-reactive protein (CRP) level of $6.0 \mathrm{mg} / \mathrm{dL}$. ESR and CRP are the most common tests to diagnose and monitor inflammatory conditions [6]. MRI showed infectious spondylitis with an abscess at the posteroinferior aspect of the L5 body and epidural enhancement at the L4-S2 level. (Figure 1a) 


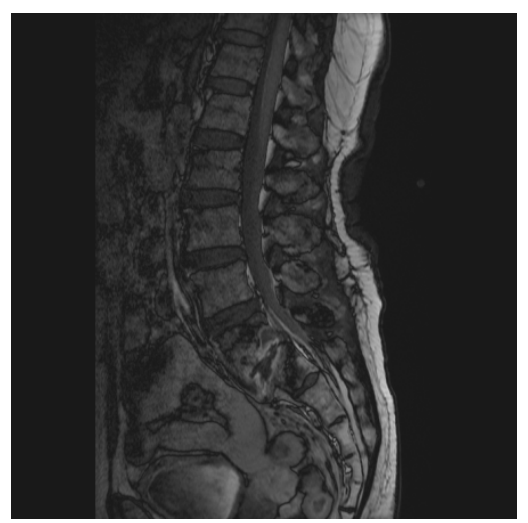

(a)

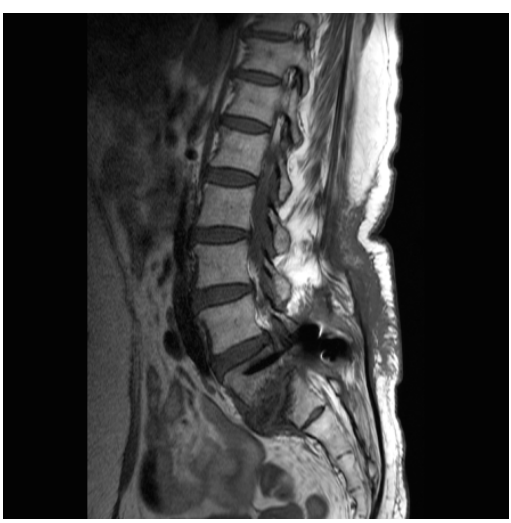

(b)

Figure 1. Spine magnetic resonance imaging (MRI) showing infectious spondylitis of L5-S1 with epidural enhancement at the L4-S1 level with decreased disc height and bone marrow signal change before treatment (a) and improvement of fluid collection with no newly developed bony destructive change at and around the L5-S1 level (b).

A two-stage operation was planned. The first surgery was performed on the 3rd day of hospitalization. Laminectomy and facetectomy were performed at the L5-S1 spine with massive irrigation. After surgical debridement and collection of culture specimens, empirical antimicrobial therapy with cefotiam was started before the culture results became available. Blood culture was performed before starting empirical antimicrobial treatment, in which no micro-organism was identified Kytococcus sedentarius was identified from a closed pus and tissue culture obtained during surgery. A VITEK ${ }^{\circledR}$ II system (bioMérieux, La BalmeLes-Grottes, France) and matrix-assisted laser desorption ionization-time of flight mass spectrometry (MALDI-TOF) (bioMerieux, Marcy-l'Etoile, France) were used to identify the causative pathogens. The antibiotic susceptibility test showed minimum inhibitory concentrations (MICs) of $\leq 0.5 \mathrm{mg} / \mathrm{L}$ for ciprofloxacin, 16 for vancomycin, $\geq 4 \mathrm{mg} / \mathrm{L}$ for oxacillin, and $\geq 32 \mathrm{mg} / \mathrm{L}$ for rifampin. Once the antimicrobial sensitivity test results became available after 14 days, the antimicrobial therapy was changed to ciprofloxacin. On the 15th day of hospitalization, a second operation was performed to secure the spine's stability by posterior lumbar interbody fusion.

Intravenous ciprofloxacin was continued for 2 weeks before hospital discharge and switched to oral ciprofloxacin, which was continued for 6 more weeks.

After a total of 8 weeks' treatment, follow-up MRI showed no fluid collection, abscess, or epidural enhancement (Figure 1b). Lab tests showed an ESR of $26 \mathrm{~mm} / \mathrm{h}$ and a CRP concentration of $0.3 \mathrm{mg} / \mathrm{dL}$.

The 6-month follow-up at the outpatient clinic showed that the patient's back pain and radiating leg pain had been alleviated. The blood tests showed an ESR of $26 \mathrm{~mm} / \mathrm{h}$ and CRP concentration of $0.2 \mathrm{mg} / \mathrm{dL}$.

\section{Discussion}

The significance of Kytococcus as a human pathogen may not have been fully recognized, or infections were previously misidentified as Micrococcus spp. [7] Kytococcus was separated from Micrococcus based on phylogenetic and chemotaxonomic analyses, with K. sedentarius the first species described in the genus Kytococcus in 1995 [8]. The recent identification of Kytococcus infection has been enabled by molecular sequencing or MALDI-TOF MS. An increased number of infections caused by K. schroeteri has been reported recently [7].

According to Shah's study on K. schroeteri infections, 13 of 19 cases were related to prostheses, while the others were pneumonia cases [7]. Only one case of postoperative spondylitis was reported in a female patient with diabetes. Among the 19 patients, 11 were immunocompromised. 
K. sedentarius is usually a skin organism that is not harmful but can be associated with infections $[1,2,9]$. Few K. sedentarius infections have been reported, including pneumonia in a patient with acute leukemia and two cases related to prostheses (Table 1). As K. sedentarius is normal skin commensal, breakage of the skin barrier due to prosthetics or injection therapy could lead to infection. To our knowledge, this is the first case of infectious spondylitis caused by K. sedentarius.

Table 1. Reported cases of Kytococcus sedentarius infection.

\begin{tabular}{|c|c|c|c|c|c|}
\hline Sex/Age (Years) & $\begin{array}{l}\text { Immunocompromising } \\
\text { Condition }\end{array}$ & $\begin{array}{l}\text { Primary Source of } \\
\text { Infection }\end{array}$ & Therapy & Outcome & Report \\
\hline $\mathrm{F} / 66$ & $\begin{array}{c}\text { End-stage renal disease } \\
\text { due to type } 2 \text { diabetes } \\
\text { mellitus }\end{array}$ & $\begin{array}{c}\text { Peritoneal } \\
\text { dialysis-associated } \\
\text { peritonitis }\end{array}$ & $\begin{array}{l}\text { Vancomycin } \\
\text { intraperitoneal } \\
\text { injection }\end{array}$ & Recovered & Chaudhary et al. [1] \\
\hline $\mathrm{M} / 55$ & Acute myeloid leukemia & $\begin{array}{l}\text { Hemorrhagic } \\
\text { pneumonia }\end{array}$ & $\begin{array}{l}\text { Teicoplanin and } \\
\text { cefepime }\end{array}$ & Deceased & Levanga et al. [2] \\
\hline $\mathrm{M} / 67$ & None & $\begin{array}{l}\text { Femoropopliteal } \\
\text { bypass graft } \\
\text { infection }\end{array}$ & $\begin{array}{l}\text { Amoxicillin- } \\
\text { clavulanate }\end{array}$ & Recovered & Dainese et al. [6] \\
\hline
\end{tabular}

Regarding the treatment of this strain, there are no formally established MIC breakpoints from the Clinical Laboratory Standards Institute (CLSI) for Kytococcus species. Therefore, the MIC breakpoints should be interpreted with caution. Kytococcus species are usually resistant to methicillin and penicillin $\mathrm{G}$ [10] but susceptible to streptomycin, novobiocin, tetracycline, vancomycin, and polymyxin B [8]. Although there are no data on in vitro susceptibility test results of fluoroquinolones for Kytococcus spp., there are data on the in vitro activity of antibiotics for Micrococcus spp. [11,12]. According to Peters, levofloxacin and ciprofloxacin were equally active against all 191 micrococcal strains tested and twofold more active than ofloxacin [11].

In the present case, as the isolate was resistant to most antimicrobial agents, including vancomycin and rifampin, the patient was treated with ciprofloxacin alone. Two reported cases of $K$. schroeteri infections were treated with fluoroquinolones. One patient with pneumonia died with ofloxacin and ceftriaxone treatment; the other was a case of prosthetic discitis that survived with ofloxacin and rifampin treatment [7]. The difference between this case and other $K$. schroeteri cases was that we treated the patient with ciprofloxacin alone, which is considered twice as effective as ofloxacin [11].

\section{Conclusions}

In summary, we described the first known case of infectious spondylitis caused by K. sedentarius, which was treated with surgery and an antibiotic agent. Although Kytococcus species are considered part of the skin's normal flora, human infections with K. sedentarius do occur, especially if they are related to invasive procedures. When culture studies show K. sedentarius in patients with infectious spondylitis, it should be considered a pathogen rather than a contaminant. In the treatment of $K$. sedentarius infection, ciprofloxacin was a successful treatment for infectious spondylitis, although more cases are needed.

Author Contributions: K.R.L., J.S.S. and S.-y.M.—conceptualization, K.R.L.-first draft, S.-y.M.editing and review. All authors have read and agreed to the published version of the manuscript.

Funding: This research received no external funding.

Institutional Review Board Statement: This case report was reviewed by the institutional review board of the hospital (IRB No.: 2021-03-030).

Informed Consent Statement: The written consent from the patient was waived.

Data Availability Statement: Data is contained within the article.

Conflicts of Interest: The authors declare no conflict of interest. 


\section{References}

1. Chaudhary, D.; Finkle, S.N. Peritoneal dialysis-associated peritonitis due to Kytococcus sedentarius. Perit. Dial. Int. J. Int. Soc. Perit. Dial. 2010, 30, 252-253. [CrossRef] [PubMed]

2. Levenga, H.; Donnelly, P.; Blijlevens, N.; Verweij, P.; Shirango, H.; de Pauw, B. Fatal hemorrhagic pneumonia caused by infection due to Kytococcus sedentarius-A pathogen or passenger? Ann. Hematol. 2003, 83, 447-449. [CrossRef] [PubMed]

3. Chan, J.F.; Wong, S.S.; Leung, S.S.; Fan, R.Y.; Ngan, A.H.; To, K.K.; Lau, S.K.P.; Yuen, K.-Y.; Woo, P.C.Y. First report of chronic implant-related septic arthritis and osteomyelitis due to Kytococcus schroeteri and a review of human K. schroeteri infections. Infection 2012, 40, 567-573. [CrossRef] [PubMed]

4. Babic, M.; Simpfendorfer, C.S. Infections of the Spine. Infect. Dis. Clin. N. Am. 2017, 31, 279-297. [CrossRef] [PubMed]

5. Vorbeck, F.; Morscher, M.; Ba-Ssalamah, A.; Imhof, H. Infectious spondylitis in adults. Radiologe 1996, 36, 795-804. [CrossRef] [PubMed]

6. Lapić, I.; Padoan, A.; Bozzato, D.; Plebani, M. Erythrocyte Sedimentation Rate and C-Reactive Protein in Acute Inflammation. Am. J. Clin. Pathol. 2020, 153, 14-29. [CrossRef] [PubMed]

7. Shah, A.S.; Vijayvargiya, P.; Jung, S.; Wilson, J.W.; Chan, J.F.; Wong, S.S.; Leung, S.S.; Fan, R.Y.; Ngan, A.H.; To, K.K.; et al. Postoperative Hardware-Related Infection from Kytococcus schroeteri: Its Association with Prosthetic Material and Hematological Malignancies-A Report of a Case and Review of Existing Literature. Case Rep. Infect. Dis. 2019, 2019, 6936472. [CrossRef] [PubMed]

8. Stackebrandt, E.; Koch, C.; Gvozdiak, O.; Schumann, P. Taxonomic dissection of the genus Micrococcus: Kocuria gen. nov., Nesterenkonia gen. nov., Kytococcus gen. nov., Dermacoccus gen. nov., and Micrococcus Cohn 1872 gen. emend. Int. J. Syst. Bacteriol. 1995, 45, 682-692. [CrossRef] [PubMed]

9. Dainese, L.; Saccu, C.; Zoli, S.; Trabattoni, P.; Guarino, A.; Cavallero, A.; Spirito, R. Vascular homograft use in a femoropopliteal rare bacterial infection bypass. Int. J. Artif. Organs. 2012, 35, 1077-1079. [CrossRef] [PubMed]

10. Mnif, B.; Boujelbène, I.; Mahjoubi, F.; Gdoura, R.; Trabelsi, I.; Moalla, S.; Frikha, I.; Kammoun, S.; Hammami, A. Endocarditis Due to Kytococcus schroeteri: Case Report and Review of the Literature. J. Clin. Microbiol. 2006, 44, 1187-1189. [CrossRef] [PubMed]

11. von Eiff, C.; Peters, G. In vitro activity of ciprofloxacin, ofloxacin, and levofloxacin against Micrococcus species and Stomatococcus mucilaginosus isolated from healthy subjects and neutropenic patients. Eur. J. Clin. Microbiol. Infect. Dis. Off. Publ. Eur. Soc. Clin. Microbiol. 1998, 17, 890-892. [CrossRef] [PubMed]

12. von Eiff, C.; Herrmann, M.; Peters, G. Antimicrobial susceptibilities of Stomatococcus mucilaginosus and of Micrococcus spp. Antimicrob. Agents Chemother. 1995, 39, 268-270. [CrossRef] [PubMed] 